\title{
The Influence of Emotional Intelligence toward Life Satisfaction of Elementary School Teachers (Case Study in South Jakarta Region)
}

\author{
Adi Teguh Suprapto ${ }^{1}$, Emny Harna Yossy $^{1}$, Sasmoko $^{1}$, Yasinta Indrianti ${ }^{1}$ \\ ${ }^{1}$ Bina Nusantara University \\ Email: aditeguhs992@gmail.com
}

\begin{abstract}
Low teachers' welfare contributes to low quality of education in Indonesia. So naturally if teachers then do side jobs in order to meet the needs of everyday life. Problem of research how tendency of Life Satisfaction and Emotional Intelligence of elementary school teachers? Research was conducted in all elementary schools in South Jakarta. Research method is explanatory and confirmatory method called Neuroresearch Method with population 697 teachers. The results is: (1) elementary school teachers in South Jakarta significantly tend to Life Satisfaction Praised significantly at $\alpha<0.05$; (2) elementary school teachers in South Jakarta were significantly more likely to have high Emotional Intelligence significantly at $\alpha<0.05$; (3) there is positive and significant influence of Emotional Intelligence to Life Satisfaction of elementary school teachers in South Jakarta is very significant at $\alpha<0.01$; (4) Emotional Intelligence is the most dominant variable determining the formation of Life Satisfaction of elementary school teachers in South Jakarta, and (5) female teachers have a more lively Life Satisfaction than male teacher significantly on $\alpha<0.05$; There is no difference in Life Satisfaction of primary school teachers in South Jakarta, if differentiated by teacher gender significantly on $\alpha<0.05$.
\end{abstract}

\section{Keywords: emotional intelligence; life satisfaction; neuroresearch}

\section{INTRODUCTION}

Education is an effort to educate the life of the nation and improve the quality of life of people in a country. By the availability of teachers have a function and a strategic role in the education process. Teacher profession has the main task of educating, teaching, guiding, and holding learners at every level of education. Based on data cited from the publication of the Central Bureau of Statistics (BPS) under the Ministry of Education and Culture during the period 2012-2014 is as in figure 1. No growth in the number of primary schools in 2014 is fixed 148.272 elementary school units. The number of elementary school teachers only increased by $0.38 \%$ in 2014 to 1.539 .819 teachers. The number of elementary students dropped by $1 \%$ to 26.504 .160 students.

Based on a survey of FGII (Indonesian Independent Teachers Federation) in mid2005 , ideally a teacher receives a monthly salary of Rp 3 million rupiah. The average income of civil servant teachers per month is $\mathrm{Rp} 1.5$ million. Teachers aids $\mathrm{Rp} 460$ thousand and teachers honorary in private schools an average of Rp 10 thousand per hour [1]. With these income conditions, it is natural that teachers then do side jobs to meet their daily needs. Some teachers are teaching in two schools, giving lessons in the 
afternoon, or being a motorcycle taxi driver, boiled noodle merchant, book dealer / LKS, mobile phone merchant, and so forth. The condition of the living needs of the unfulfilled teaching profession makes life satisfaction or Life Satisfaction from the profession of teachers low. Even teachers are forced to work harder outside the work of teachers, to simply be able to meet the daily needs of families, increasingly pressing the level of Life Satisfaction of the teaching profession.

In this case later, Law 14 of 2005 emerged, namely the teacher has a position as professional equivalent to other functional personnel in Indonesia. Teachers are entitled to income above minimum living requirement which includes basic salary, plus other benefits such as professional allowance, functional and special allowance stipulated under the principle of award on the basis of achievement [2]. Through the law, it is expected that life satisfaction or Life Satisfaction from the profession of teachers can then be increased and even prosperous. Consequently, in Law 14 of 2005 it is also mentioned that teachers are required to have academic qualifications (undergraduate), competence skills, and educator certificates. Teacher competence includes pedagogic competence, personality competence, social competence, and professional competence. A series of these capability requirements then elicits what is called Emotional Intelligence or Emotion (comprehension).

Emotional Intelligence deals with many aspects, one of which is problem solving and decision making where they will always involve thoughts and feelings or logic and intuition. This provides the basis for this research to see further the impact of Emotional Intelligence on Life Satisfaction in elementary school teachers in South Jakarta.

\section{THEORETICAL STUDIES, FRAMEWORK AND HYPOTHESES}

\section{Life Satisfaction}

Diener and Biswas-Diener stated that Life Satisfaction is a cognitive assessment of how well and satisfying things individuals have done in their lives thoroughly and over the key areas of their life (Domain Satisfaction) such as relationships Interpersonal, health, work, income, spirituality and leisure activities. Life Satisfaction is comprising an overall summary of one's life as measured by the experience of his life. It consists of a person's judgment of the relative quality of his life [3]. Life Satisfaction, in contrast, refers to the long-term evaluation of one's life, both positive and negative experiences [4]

Based on some of the above definition, the Life Satisfaction in this research is the degree of one's satisfaction on life in live is characterized by 1) satisfaction on the standard of living owned; 2) the satisfaction of the present life; 3) satisfaction with future life plans and 4) satisfaction with life in the past.

\section{Emotional Intelligence}

Salovey and Mayer define emotional intelligence as "the ability to monitor their own feelings and others, to differentiate between them, and use this information to guide one's thoughts and actions." Human resources that have the ability to communicate with each other effectively can lead the organization to success and effectiveness [5] 
Because individuals with high emotional intelligence have greater awareness of their emotions and greater capacity to integrate emotional experiences with thoughts and actions, emotional intelligence has a role in career exploration and career decision making [6]

The conceptualisation of the Emotional intelligence, based on the perspective of the emotional functionalist, suggests that people who are able to express and understand emotions determine the meaning of emotional experience and manage their feelings better in psychologically and socially adjusting [7]. Emotional intelligence theory suggests the opposite: emotions make adaptive cognitive processes and individuals can think rationally about emotions [8].

Emotional Intelligence in the study [9] has been found to be positively correlated with the level of well-being. This can affect work attitudes, improve altruistic behavior, improve work output and curb interpersonal and stress related conflicts.

Recent research has shown that Emotional Intelligence (EI) is associated with depression. Results confirmed the gender differences in EI capabilities, with higher rates in women compared with men [10]

Research [10] examines whether the underlying measurement structure of EI properties is equivalent across the sexes and age groups. The sample consists of 2,919 adolescents, youth and adults. Confirmatory factor analysis results reveal that configured, metric, scalar and structural invariance exist throughout the sex and age samples.

Emotional Intelligence as a set of competencies, as follows: self-awareness, selfregulation, social awareness, and relationship management. Emotional intelligence is summarized in four dimensions, namely:

a. Self-awareness of how one recognizes, understands and knows the cause of what he feels

b. Social awareness, that is, the human ability to understand the emotions of others

c. Self-regulation, namely the ability to direct behavior and manage emotions to all people and situations

d. Relationship management, the ability of personal emotional awareness and others to manage relationships well.

The concept of emotional intelligence in this study refers to the above understanding of the ability of individuals in managing their emotions so that it can develop effectively with reference to four dimensions, namely 1) self-awareness: 2) Social Awareness; 3) self-regulation; 4) relationship management.

\section{Framework}

1. Elementary school teachers in South Jakarta tend to have a moderate Life Satisfaction

The ultimate goal of every job is the fulfillment of human life needs which will ultimately bring a satisfied condition for his life. The concept of life satisfaction is based on how a person evaluates himself based on established standards.

Before the authors determine the conclusion of the author first set the category as much as 3 categories: Life Satisfaction is low, moderate and high

Based on the above description, it is reasonable to assume that elementary school teachers in South Jakarta tend to have a moderate Life Satisfaction. 
2. Elementary school teachers in South Jakarta tend to have moderate Emotional Intelligence.

High demands and student diversity are external factors that will help teachers in cooking their skills in managing emotions. With proper management, the impact will ultimately lead to the performance and success of students in achieving academic competence.

From various research results, it has been proven that emotional intelligence has a far more significant role than intellectual intelligence.

Before the authors determine the conclusion of the author first set the category as much as 3 categories: Emotional Intelligence is low, moderate and high

Based on the above description, it should be assumed that elementary school teachers in South Jakarta tend to have a moderate Emotional Intelligence.

There is Influence of Emotional Intelligence to Life Satisfaction of Elementary School Teachers in South Jakarta

The research results of Anggit Prasetiyo and Inge Andriani prove Wuryanano statement in that the higher one's Emotional Intelligence will be the better the satisfaction and the happiness he felt. Emotional Intelligence plays an important role in achieving such satisfaction.

Life Satisfaction can be achieved when a teacher is able to display performance in accordance with the standards and able to provide a positive impact for students. This impact will be felt when students experience the full involvement of the teacher during the learning process which of course will not be separated from the emotional aspects associated with emotional management or more often known as Emotional Intelligence.

Based on the above description, then it should be suspected that there is influence of Emotional Intelligence to Life Satisfaction of Elementary School Teachers in South Jakarta.

Life Satisfaction is a cognitive assessment made consciously of one's life according to the criteria of life it has Pavot \& Diener. Life Satisfaction is a cognitive assessment made consciously of one's life according to the criteria of life it has. Argyle says that individuals with working status are happier than individuals who are unemployed and so do professionals and skilled individuals appear happier than unskilled individuals.

The condition when a person feels satisfied with his life is a thorough assessment of the current state by involving multiple points of view. This is the basis for this research to present the concept of Life Satisfaction seen from 4 dimensions and 21 indicators, namely:

a. Dimensions of satisfaction over the standard of living owned by indicators:

1) Have a good Interpersonal Relationship

2) Have good health

3) Well established in work

4) Have a satisfactory income

5) Running Have a Good Spiritual Life

b. Dimensions are satisfied with the current life with indicators:

1) Good Interpersonal Relationships

2) Grateful for his health

3) Grateful for the work

4) Grateful for the income

5) Be grateful for the confidence of his spirituality life

6) Have activities run 
c. Satisfied with future life plans with indicators:

1) Satisfied in Working

2) Satisfied in Building Relationships with Others

3) Satisfied Build a Blessing Spiritual Life

d. Satisfied with life in the past with indicators:

1) Satisfied with the quality of life in the past

2) Satisfied for Efforts in Maintaining Your Health

3) Satisfaction with the work initiated

4) Satisfied of Revenue

5) Satisfied that He Has Built a Good Spiritual Life

6) Satisfied with Timely Use.

With reference to the above dimensions and indicators, it should be assumed that Relantionship Management (X4) is the most dominant dimension of Life Satisfaction formation in elementary school teachers in South Jakarta.

3. There is a difference in Life Satisfaction if differentiated differences in the background of teachers in elementary school in South Jakarta.

Differences in situation conditions can affect the concept of Life Satisfaction. It relates to the achievement of performance that relies on process and time of achievement. It is therefore to be expected that gender differences, length of work and certification status as educators affect Life Satisfaction.

Women have lower salary expectations than men and have a tendency to get the same level of satisfaction as men with lower salaries or more satisfaction than men with the same salary. Based on the above description, it is reasonable to expect that there is a difference between Life Satisfaction in Elementary School Teachers in South Jakarta if reviewed from the gender.

\section{The Hypothesis}

Hypothesis testing is made based on the results of research framework thinking, namely:

1. Elementary school teachers in South Jakarta are significantly more likely to have a moderate Life Satisfaction.

2. Elementary school teachers in South Jakarta are significantly more likely to have moderate Emotional Intelligence.

3. There is a significant Influence of Emotional Intelligence on Life Satisfaction of Elementary School Teachers in South Jakarta.

4. The most determining dimension of Life Satisfaction of teachers in elementary school in South Jakarta.

5. There is a difference in Life Satisfaction if differentiated differences in the background of teachers in elementary school in South Jakarta.

\section{RESEARCH METHODS}

The research method used is exploratory and confirmatory correlational survey, so the research is categorized as neuororesearch grouped into survey type, because this research uses representative samples to draw conclusions in the population, even though the population condition is unreachable [12-14]. 
Researchers want to study or explore in depth the influence of independent variable that is Emotional Intelligence $(\mathrm{X})$ which functioned as exogenous variables to dependent variable that is Life Satisfaction of teachers in elementary school in South Jakarta (Y). This explanatory research is included in the clump of research development model or commonly called Structural Equation Modeling (SEM). Simply put, the plan or academic prediction of the relationship pattern between research variables in this study can be described as follows.

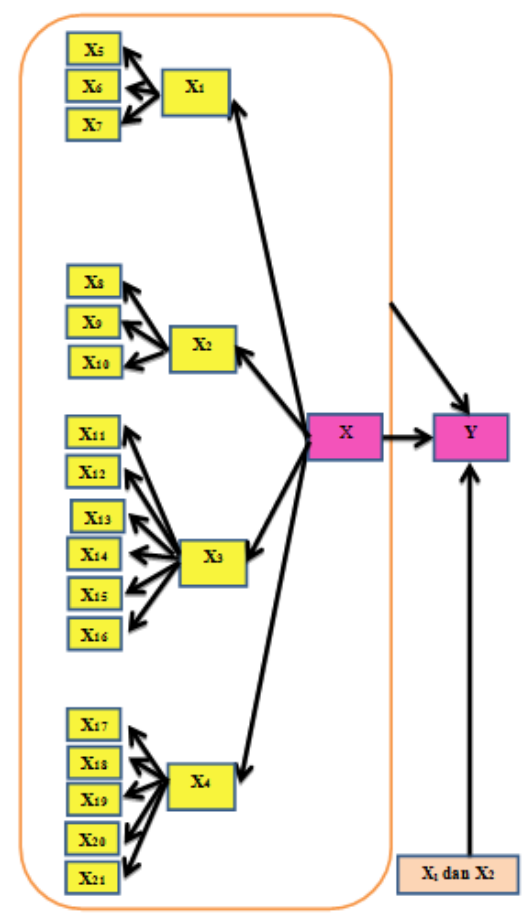

Figure 1. Design Pattern Relationships between Variables Based on Construct

Information:

$\mathrm{Y}=$ Life Satisfaction of teachers in elementary school in South Jakarta (Dependent variable that acts as endogenous variable)

$\mathrm{X}=$ Emotional Intelligence of teachers in elementary school in South Jakarta (Independent variable)

Exogenous Variable consists of:

$\mathrm{X} 1$ = Dimension of Self-Awareness

X5 $=$ Indicators Have Awareness in Emotions

X6 = Indicators Have Self Assessing Ability

$\mathrm{X} 7=$ Self-Confidence Indicator

X2 $=$ The Dimension of Social Awareness

$\mathrm{X} 8$ = Indicator Has Empathy

X9 = Indicators Provide the Best Service

X10 = Organizational Aware Indicators

X3 = Self-Regulatory Dimension

X11 = Indicators Able to Control Your Emotions

X12 $=$ Trustable Indicators 
X13 $=$ Thorough Indicators

$\mathrm{X} 14$ = Indicators Be Adaptable

X15 = Indicator Has Achievement Impulse

X16 = Indicators Have Initiative

X4 = Dimension Relationship Management

X17 = Indicators Seeking to Advance Others

$\mathrm{X} 18=$ Indicators Affecting Others

X19 = Indicator Able to Lead

$\mathrm{X} 20=$ Indicators for Building Bonds

$\mathrm{X} 21$ = Indicators Able to Cooperate

\section{POPULATION AND SAMPLE}

In this study, the population is all elementary school teachers in South Jakarta. While Cluster random sampling is Cluster Purposive Random Sampling technique that is first done by cluster. The second stage is to set the sample by purposive. The next stage after determining the selected elementary school, then researchers set the sample members randomly, because the assumption that all clusters (cluster purposive) that has been established researchers are homogeneous and have the same opportunity. The number of samples for this study was 697 teachers. The sample for the instrument test is set by 30 teachers.

\section{DATA COLLECTION TECHNIQUE}

Methods and data collection tools used in this study is a questionnaire method. This research has 2 (two) questionnaire that is to measure variable "Life Satisfaction Teachers in Elementary School in South Jakarta (Y) and Emotional Intelligence (X). This method is used to obtain primary data, i.e. data obtained directly from research subjects through questionnaires. Questionnaire on "Life Satisfaction Teachers in Elementary School in South Jakarta (Y) use questionnaire with questionnaire Likert Scale Model with range of data scale 1 to 5. Scale of questionnaire data in this research is defined as continuum scale. The questionnaire about "Emotional Intelligence (X) uses a Likert Scale Model Questionnaire with a data scale range of 1 to 5. The data scale of the questionnaire in this study is defined as the continuum scale. All questionnaires are filled by teachers.

Life Satisfaction of Elementary School Teachers in South Jakarta (Y)

The Life Satisfaction (Y) instrument as a valid instrument circulated to the sample consists of 22 items. With the reliability indexes of internal consistency type through the alpha formula is 0.8623 .

Emotional Intelligence of Elementary School Teachers in South Jakarta (X)

The Emotional Intelligence Instrument $(\mathrm{X})$ as a valid instrument circulated to the sample consists of 29 items. With the reliability indexes of internal consistency type through the alpha formula is 0.9281 . 


\section{RESULTS OF EXPLLANATORY RESEARCH ABOUT THE INFLUENCE OF EMOTIONAL INTELLIGENCE (X) ON LIFE SATISFACTION (Y) PRIMARY SCHOOL TEACHERS IN SOUTH JAKARTA}

Description of Life Satisfaction Data (Y)

Based on the sample data of 697 people, having a theoretical score between 22 to 110; Empirical score between 31 to 74; Mean of 52.2683; Median of 52.0000; Mode of 50.00 and standard deviation of 5.73340 .

Data Description Variable Emotional Intelligence (X)

Based on the sample data of 697 people, having a theoretical score between 29 to 145; Empirical score between 30 to 94; Mean of 60.5925; Median of 61.0000; Mode of 62.00, and standard deviation of 9.10683 .

Description of Data Background Data of Teacher consists of Gender (X5), Working Time (X6), and Status Certification (X7)

a. Gender

Based on the sample data of 697 people, it is found that most teachers come from male gender that is 500 people $(71.7 \%)$ and the least comes from female gender that is as much as 197 people $(28.3 \%)$.

b. Length of Work

Based on the sample data of 697 people, it is found that teachers who work $<5$ years are 305 people (43.8\%), 5-10 years of 30 people (4.3\%), 10-15 years of 170 people $(24.4 \%)$, And $>15$ years ie 192 people $(27.5 \%)$.

c. Certification Status

Based on the sample data of 697 people, then found a certified teacher that is 511 people $(73.3 \%)$ and teachers who have not certification that is 186 people $(26.7 \%)$.

\section{Test Requirements Analysis}

Test of Data Normality of Life Satisfaction Variable (Y)

Test of data variable normality of Life Satisfaction (Y) is done by Estimation of Proportion through formula Blom with approach of Q-Q Plot. The Q-Q Approach Plot was taken because the sample size was $>200$ people.

Based on the calculation of Normal Q-Q Plot of variable data of Life Satisfaction (Y), it appears that the data distribution shows normal, the distribution of data tends to lead to the normal line, and the data distribution has no outlier. Likewise, when viewed from the Detrended Normal Q-Q Plot, the data distribution does not depict a sinus or cosine curve.

So it can be concluded that the distribution of data variable Life Satisfaction (Y) has a normal distribution.

Test Data Normality Data Variable Emotional Intelligence (X)

The data normality test of Emotional Intelligence $(\mathrm{X})$ variable is done by Proportion Estimation through Blom formula with Q-Q Plot approach. The Q-Q Approach Plot was taken because the sample size was> 200 people.

Based on the calculation of Normal Q-Q Plot of data of Emotional Intelligence (X) variable, it appears that the data distribution shows normal, that the data distribution tends to lead to the normal line, and the data distribution has no outlier. 
Likewise, when viewed from the Detrended Normal Q-Q Plot it, the data distribution does not depict the sinus or cosine curve.

So it can be concluded that the distribution of Emotional Intelligence (X) variable data has a normal distribution.

\section{Linearity Test}

Linearity Test of Line Relationship of Emotional Intelligence (X) Variables on Life Satisfaction Variable (Y)

Linearity test is calculated by linear regression error test or linearity test of deviation from linearity. The variable of Emotional Intelligence $(\mathrm{X})$ to Life Satisfaction $(\mathrm{Y})$ variable is $\mathrm{F}$ equal to 1.816 and significance value of 0.001 is very significant at $\alpha<0.05$.

Thus the relationship of the Emotional Intelligence $(\mathrm{X})$ variable to the Life Satisfaction (Y) variable is nonlinear.

Because it is non-linear, then the curve estimation analysis is done on 11 lines, and the result of Linear $F$ test of 206.68 with significance value equal to 0.001 is very significant at $\alpha<0.05$. Thus the relationship of the Emotional Intelligence (X) variable to the Life Satisfaction (Y) variable is still in linear tolerance.

Based on the results of the above analysis, it can be concluded that the relationship of Emotional Intelligence $(\mathrm{X})$ variable to Life Satisfaction $(\mathrm{Y})$ variable is linear.

\section{HYPOTHESIS TESTING}

Hypothesis Test 1: Elementary School Teachers in South Jakarta Significantly Inclined Life Satisfaction (Y)

In proving Life Satisfaction of Elementary School Teachers in South Jakarta (Y), researchers in this case set 3 categories are: (a) Life Satisfaction low; (B) Medium Life Satisfaction and (c) High Life Satisfaction.

Data analysis was done with confidence interval at significance level 5\%, and produced lower and upper boundary between 51.8419 up to 52.6947.

Based on these results, it can be concluded that the elementary school teachers in South Jakarta, the condition tends to Life Satisfaction is significantly on $\alpha<0.05$.

Based on the results of the above research, it can be concluded that the first hypothesis that reads " Elementary School Teachers in South Jakarta Significantly Tend Life Satisfaction (Y)" in this study proved.

Hypothesis 2 Test: Elementary School Teachers in South Jakarta Significantly Tends to Emotional Intelligence (X)

In proving Emotional Intelligence of Elementary School Teachers in South Jakarta (X), the researcher in this case set 3 (three) categories that Elementary School Teachers in South Jakarta have Emotional Intelligence: (a) low; (B) medium and (c) high.

Data analysis was done with confidence interval at significance level $5 \%$, and produced lower and upper boundary between 59.9153 until 61.2698. 
Based on these results, it can be concluded that the elementary school teachers in South Jakarta, the condition tends to have Emotional Intelligence Medium significantly at $\alpha<0.05$.

Based on the results of the above research, it can be concluded that the first hypothesis which reads " Elementary School Teachers in South Jakarta Significantly Tend Emotional Intelligence (X)" in this study proved.

Hypothesis 3 Test: There is Influence between Emotional Intelligence (X) Significantly to Life Satisfaction (Y)

TABLE I. MODEL SUMMARY

\begin{tabular}{|l|l|l|l|l|}
\hline Model & $\mathrm{R}$ & R Square & $\begin{array}{l}\text { Adjusted } \\
\text { Square }\end{array}$ & $\begin{array}{l}\text { Std. Error of the } \\
\text { Estimate }\end{array}$ \\
\hline 1 & $.468^{\mathrm{a}}$ & .219 & .218 & 5.07092 \\
\hline
\end{tabular}

a. Predictors: (Constant), $\mathrm{x}$

TABLE II. ANOVA ${ }^{\mathrm{a}}$

\begin{tabular}{|ll|l|l|l|l|l|}
\hline Model & & Sum of Squares & Df & Mean Square & F & Sig. \\
\hline 1 & Regression & 5007.436 & 1 & 5007.436 & 194.734 & $.000^{\mathrm{b}}$ \\
& Residual & 17871.393 & 695 & 25.714 & & \\
& Total & 22878.829 & 696 & & & \\
\hline
\end{tabular}

a. Dependent Variable: y

b. Predictors: (Constant), $\mathrm{x}$

TABLE III. COEFFICIENTS ${ }^{\mathrm{a}}$

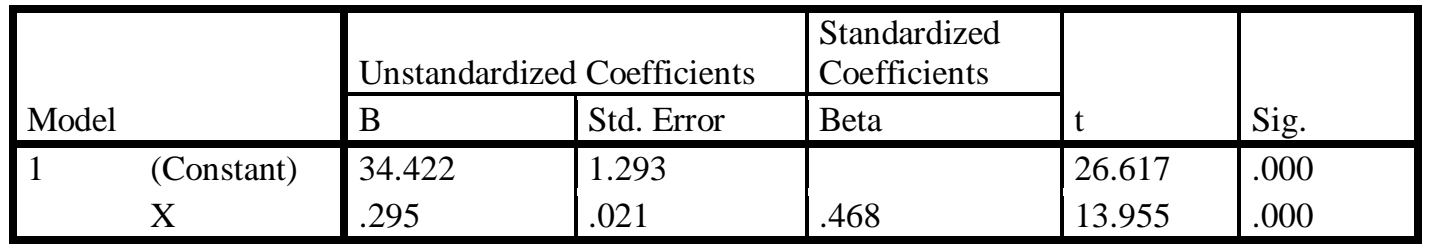

a. Dependent Variable: $y$

The result of relationship analysis in the sample between variables Emotional Intelligence (X) with Life Satisfaction (Y) variable is ryx of 0.468 is having a positive relationship. Determination of variance that illustrates the closeness of the relationship between variables Emotional Intelligence $(\mathrm{X})$ with Life Satisfaction (Y) variable of 0.218 . This means that the contribution of Variable Emotional Intelligence $(\mathrm{X})$ to Life Satisfaction (Y) variable is $21.8 \%$.

While the condition in the population depicted through t result of 13,955 is very significant at $\alpha<0.01$. So the relationship between variables Emotional Intelligence (X) with Life Satisfaction (Y) variable in the population is also positive and the contribution of Emotional Intelligence $(\mathrm{X})$ variable to Life Satisfaction (Y) variable is $21.8 \%$.

The influence of Variable Emotional Intelligence (X) to Life Satisfaction (Y) variable in the sample is depicted by linear regression equation in the sample of Emotional Intelligence $(\mathrm{X})$ variable to Life Satisfaction $(\mathrm{Y})$ variable depicted by $\hat{\mathrm{Y}}=$ $34.422+0.295 \mathrm{X}$. That is, if the elementary school teachers in South Jakarta (X) are increased through 1 (one) program or 1 (one) treatment, then Life Satisfaction (Y) will improve 0.295 times from current condition. While the influence of Emotional 
Intelligence Variable (X) on Life Satisfaction (Y) variable in population yielded $\mathrm{F}$ equal to 194.734 with significance value 0.000 is very significant at $\alpha<0.01$. So if elementary school teachers of South Jakarta (X) are increased through 1 (one) program or 1 (one) treatment, then Life Satisfaction (Y) will improve 0.295 times from current condition.

Based on the results of hypothesis test above, the third hypothesis that reads "there is influence Emotional Intelligence (X) to Life Satisfaction (Y) of elementary school teachers in South Jakarta" in this study proved.

Hypothesis Test 4: Relationship Management is the Most Dominant Dimension to determine the formation of Life Satisfaction (Y)

In proving hypothesis 5, the analytical approach is defined by Binary Segmentation which is then called Classification and Regression Trees. In this analysis, the researchers set the Prunning of Depth by 2; Parent of 2; And Child equal to 1 , with significance level $\alpha<0.05$. The result is as follows.

The result of analysis shows that Relationship Management (X4) is the most dominant dimension to determine the realization of Life Satisfaction (Y) variable. The more the elementary school teachers are enhanced by Relationship Management (X4), the Life Satisfaction (Y) will increase 6.0258 times from the current condition of Life Satisfaction (Y).

Based on the results of hypothesis test above, the fourth hypothesis which reads "Relationship Management is the Most Dominant Dimension to determine the formation of Life Satisfaction (Y) Elementary School Teachers in South Jakarta" in this study proved.

Hypothesis 5 Test: There is a Life Satisfaction Difference (Y), if Differentiated Background Teachers Elementary School in South Jakarta if viewed from Gender

Test of life satisfaction differences $(y)$ if differentiated teacher's gender (x10)

TABLE IV. GROUP STATISTICS

\begin{tabular}{|l|l|l|l|l|l|}
\hline & sexx5 & N & Mean & Std. Deviation & Std. Error Mean \\
\hline Y & Man & 500 & 51.8520 & 5.80772 & .25973 \\
& Woman & 197 & 53.3249 & 5.41220 & .38560 \\
\hline
\end{tabular}

\begin{tabular}{|c|c|c|c|c|c|c|c|c|c|}
\hline & \multicolumn{2}{|c|}{$\begin{array}{l}\text { Levene's Test } \\
\text { for Equality } \\
\text { of Variances }\end{array}$} & \multicolumn{7}{|c|}{ t-test for Equality of Means } \\
\hline & \multirow[b]{2}{*}{ F } & \multirow[b]{2}{*}{ Sig. } & \multirow[b]{2}{*}{ T } & \multirow[b]{2}{*}{$\mathrm{df}$} & \multirow{2}{*}{$\begin{array}{l}\text { Sig. } \\
(2- \\
\text { tailed) }\end{array}$} & \multirow{2}{*}{$\begin{array}{l}\text { Mean } \\
\text { Difference }\end{array}$} & \multirow{2}{*}{$\begin{array}{l}\text { Std. Error } \\
\text { Difference }\end{array}$} & \multicolumn{2}{|c|}{$\begin{array}{l}95 \% \text { Confidence } \\
\text { Interval of the } \\
\text { Difference }\end{array}$} \\
\hline & & & & & & & & Lower & Upper \\
\hline $\begin{array}{l}\text { y } \begin{array}{l}\text { Equal } \\
\text { variances } \\
\text { assumed }\end{array} \\
\text { asumed }\end{array}$ & 1.966 & .161 & -3.072 & 695 & .002 & -1.47287 & .47939 & -2.41411 & -.53164 \\
\hline $\begin{array}{l}\text { Equal } \\
\text { variances } \\
\text { not } \\
\text { assumed }\end{array}$ & & & -3.168 & 383.208 & .002 & -1.47287 & .46492 & -2.38698 & -.55876 \\
\hline
\end{tabular}

Test requirements analysis in the form of homogeneity test done with Levene Test produced $F$ equal to 1.966 is nonsignifikan at $\alpha>0.05$. Thus, the variety of males with female variety in terms of Life Satisfaction (Y) is homogeneous. Therefore $\mathrm{t} t=3.168$ is significant at $\alpha<0.05$. That is, there is a difference in the likelihood of Life Satisfaction (Y). 
Elementary School Teachers in South Jakarta, The Condition Tends Life Satisfaction Moderately significant at $\alpha<0.05$.

\section{CONCLUSIONS AND RECOMMENDATIONS}

\section{Conclusion}

Elementary school teachers in South Jakarta are significantly more likely have a moderate level of Life Satisfaction, have a moderate degree of Emotional Intelligence. There is a significant influence between Emotional Intelligence on Life Satisfaction of Elementary School Teachers in South Jakarta. Relationship Management is the most dominant dimension to determine the formation of Life Satisfaction. There is a difference in Life Satisfaction, if differentiated background of elementary school teacher in South Jakarta if viewed from gender.

\section{Suggestion}

For Educational Institutions, In order to pay more attention to the welfare of teachers by providing support in the form of trainings that can improve the quality of teachers both hard skills and soft skills with the aim that teachers can be equivalent to professionals.

For Teachers, Teachers are expected to develop their tasks well so that their students can become qualified individuals useful to others, and can also optimize their ability to be equal with professionals.

\section{REFERENCES}

[1] Al-jawi, S.M., 2012. Pendidikan Di Indonesia: Masalah Dan Solusinya. Potret Pendidikan Indonesia Antaray Konsep, Reality dan Solusi, (May 2006), pp.1-8.

[2] Pemerintah RI, 2005. Undang-undang Republik Indonesia Nomor 14 Tahun 2005 tentang Guru dan Dosen. Produk Hukum, p.54

[3] Hofmann, W. et al., 2014. Yes, But Are They Happy? Effects of Trait Self-Control on Affective Well-Being and Life Satisfaction. Journal of Personality, 82(4), pp.265-277.

[4] De Neve, J.-E. \& Oswald, A.J., 2012. Estimating the influence of life satisfaction and positive affect on later income using sibling fixed effects. Proceedings of the National Academy of Sciences of the United States of America, 109(49), pp.19953-8. Available at: http://www.pubmedcentral.nih.gov/articlerender.fcgi?artid=3523830\&tool=pmcentrez\&rendertyp $\mathrm{e}=$ abstract.

[5] Aghdasi, S., Kiamanesh, A.R. \& Ebrahim, A.N., 2011. Emotional intelligence and organizational commitment: Testing the mediatory role of occupational stress and job satisfaction. Procedia Social and Behavioral Sciences, 29, pp.1965-1976. Available at: http://dx.doi.org/10.1016/j.sbspro.2011.11.447.

[6] Di Fabio, a. et al., 2012. Career Indecision Versus Indecisiveness: Associations With Personality Traits and Emotional Intelligence. Journal of Career Assessment, 21(1), pp.42-56.

[7] Salguero, J.M., Extremera, N. \& Fernández-Berrocal, P., 2012. Emotional intelligence and depression: The moderator role of gender. Personality and Individual Differences, 53(1), pp.2932.

[8] Brackett, M.A. et al, 2011. Emotional Intelligence: Impications for Personal, Social, Academic, and Workplace Success. Sosial and Personalty Psychology Compass, 5(1), pp.88-103. 
[9] Karimi, L. et al., 2014. Emotional rescue: The role of emotional intelligence and emotional labour on well-being and job-stress among community nurses. Journal of Advanced Nursing, 70(1), pp.176-186.

[10] Tsaousis, I. \& Kazi, S., 2013. Factorial invariance and latent mean differences of scores on trait emotional intelligence across gender and age. Personality and Individual Differences, 54(2), pp.169-173.

[11] Easterlin, R. a. et al., 2012. From the Cover: China's life satisfaction, 1990-2010. Proceedings of the National Academy of Sciences, 109(25), pp.9775-9780.

[12]Fios, F., Sasmoko \& Gea, A.A., 2016. Neuro-Research Method: A Synthesis Between Hermeneutics and Positivism. Advanced Science Letters, 22(9), pp.2202-2206. Available at: http://www.ingentaconnect.com/content/10.1166/asl.2016.7565.

[13] Sasmoko; Ying, Y., 2015. Construct Validity in NeuroResearch. Advanced Science Letters, 21(7), pp.2438-2441. Available at: http://www.scopus.com/inward/record.url?eid=2-s2.084946963005\&partnerID=tZOtx3y1.

[14] Sasmoko \& Anggriyani, D., 2016. Neuroresearch (A Model of Research Method). In A. Khan et al., eds. Research on Educational Studies. New Delhi: Serial Publications PVT. LTD, pp. 33-45.

[15] Schlenker, B.R., Chambers, J.R. \& Le, B.M., 2012. Conservatives are happier than liberals, but why? Political ideology, personality, and life satisfaction. Journal of Research in Personality, 46(2), pp.127-146. Available at: http://dx.doi.org/10.1016/j.jrp.2011.12.009. 